Uluslararası Yönetim İktisat ve İşletme Dergisi, ICAFR 16 Özel Sayısı

Int. Journal of Management Economics and Business, ICAFR 16 Special Issue

\title{
15. YY. OSMANLI MUHASEBESINDE KÂRIN SERMAYE PAYLARIYLA ORANTILI DAĞITIMININ HESAPLANMASINA ILLISTKİN BİR ÖRNEK
}

\author{
Öğr. Gör. Metehan KÜÇÜKER \\ Bülent Ecevit Üniversitesi, Çaycuma Meslek Yüksekokulu \\ metehankucuker@beun.edu.tr \\ Prof. Dr. Ahmet Vecdi CAN \\ Sakarya Üniversitesi, İşletme Fakültesi \\ acan@sakarya.edu.tr
}

ÖZET

1494 yllında kaleme alınan Mecma'ü'l-Kavâ'id adlı eserin incelenmesi ve dönemin muhasebe işleyişi hakkında bilgi sahibi olunması amaçlanan bu çalışmada, öncelikle Osmanl dönemi muhasebe sistemine genel olarak değinilmiş daha sonra Mecma 'ü'l-Kavâ'id adlı eser ve yazarı hakkında bilgi verilerek eserde yer alan çözümlü bir örnek ele alınmıștır.

Anahtar Kelimeler: Muhasebe Tarihi, Osmanlı Muhasebesi, Mecma '̈̈’l-Kavâ 'id, Muhyeddin Muhammed

\section{IN 15TH CENTURY ACCOUNTING IN THE OTTOMAN EMPIRE, AN EXAMPLE REGARDING CALCULATION OF CAPITAL GAIN DISTRIBUTION WITH SHARE}

\begin{abstract}
The purpose of the study was to examine a book called Mecma' $̈$ 'l Kava'id which was written in 1494 and acquire knowledge about the functioning of the accounting in that period. In the first part of the study; it was mentioned as a general accounting system of the Ottoman period and thereafter it was discussed with an example by being given a book called Mecma'ü'l Kava'id and information about its author.

Keywords: History of Accounting, Accounting in the Ottoman Empire, Mecma ' $\ddot{\text { ' }}$ lKavâ 'id, Muhyeddin Muhammed

\section{Giriș}

Dünya muhasebe tarihi genel bir bakış açısı ile incelendiğinde muhasebe temel ilkelerinin ve bir takım kurallarının milattan üç bin yıl kadar önce Mısır'da ortaya çıkmaya başladığı görülmektedir. Daha sonra ise Finikeliler, Hintliler, Yunanlılar, Çinliler ve Romalılar arasında gelişen ticaret münasebetlerinin muhasebenin
\end{abstract}




\section{Uluslararası Yönetim İktisat ve İsletme Dergisi, ICAFR 16 Özel Sayısı Int. Journal of Management Economics and Business, ICAFR 16 Special Issue}

gelişmesinde ve yaygınlaşmasında etkili olduğu ileri sürülmüştür. Muhasebenin Orta Asya'dan Roma'ya gelişinin ise ipek yoluyla sağlandığı da açıktır buna karşılık muhasebenin, 1494 yılında Luca Pacioli tarafindan geliştirildiği dünyaya ilan edilmiştir (Pur, 1995: 94). Bütün bu tarih süreci içinde Türklerin olmaması ve adının vurgulanmaması ise oldukça düşündürücüdür. Zira tarih sahnesinde başrole sahip Türklerin, savaşan, hayvancılıkla ilgilenen göçebe olarak çadırlarda yaşayan bir millet olması bilim ve kültürden uzak olduğu anlamına gelmez. Aksine Türkler tarih sahnesin bütün bilim dallarında olduğu gibi muhasebe bilimine de öncülük etmiş ve bunu önemli eserlerle ortaya koymuş bir millettir. Göktürk ve Uygur dönemlerine ait el yazmaları ve bazı ticaret vesikalarından elde edilen bilgiler, Türklerin İslamiyet'i kabulünden sonra kaleme alınmış Kutadgu Bilig ve Dîvânü Lugati't-Türk adlı eserlerde yer alan muhasebe ile ilgili terim ve kurallar ve Osmanlı İmparatorluğu döneminde 500 yıl boyunca kullanılan merdiven kayıt yöntemi bu durumun en belirgin göstergelerindendir.

Muhasebe tarihi çalışmalarının birçoğunun muhasebeyi çift taraflı kayıt tekniğine bir başka ifadeyle Luca Pacioli'ye dayandırdığı görülmektedir. Bu durumun temel nedeni ise Türklerle ilgili muhasebe tarihi bilgi ve belgelerin yetersiz olması ve muhasebe alanında çalışan akademisyenlerin muhasebe tarihi alanına yeterine eğilmemesidir. Ne var ki bilimin ve uygulamanın gelişimi, belirli bir ölçüde de olsa, tarihi gelişimin etkisi altındadır. O halde bugünkü muhasebe bilim ve uygulamasının içinde bulunanların, muhasebenin dününü bilmek ve onun tarihi ile ilgilenme zorunluluğu vardır. (Güvemli 1995: 5). Bu çalışma söz konusu bu zorunluluğun yerine getirilmesi ve Türklerle ilgili muhasebe tarihi bilgilerinin ortaya konulması açısından önem arz etmektedir. Çalışmada 1494 yılında, Hacı Atmacaoğlu Muhyeddin Muhammed tarafından kaleme alınan Mecma'ü'l-Kavâ'id adlı eser tanıtılarak Türk muhasebe tarihi açısından önemine değinilecek ve eserde yer alan bir çözümlü örnek incelenecektir.

\section{Osmanlı İmparatorluğu Döneminde Muhasebeye Genel Bakış}

Osmanlı İmparatorluğu dönemi öncesinde hüküm süren Türk devletlerinde olduğu gibi, Osmanlı İmparatorluğu döneminde de muhasebe oldukça önemli bir yere sahiptir. Muhasebecilik ise oldukça saygın bir meslek halini almıştır. Bu dönemde tutulan mali defter ve kayıtlarda divan rakamları ve siyakat yazısı kullanılmıştır. Siyakat yazısı olarak bilinen ve siyakat rakamlarının kullanıldığı bu yazı türü herkesin okuyamayacağı ancak konu ile ilgili uzmanların okuyabileceği çoğunlukla mali işlerde kullanılan kimilerine göre şifreli bir yazı kimilerine göre ise bir meslek dili olarak tanımlanmaktadır. Osmanlı Devleti'nde Siyakat yazısının kullanılmasıyla birlikte "Merdiven Yöntemi" olarak adlandırılan ve bilinen en eski kayıt usullerinden biri olduğu kabul edilen yöntem de kullanılmaya başlanmıştır (Can ve Esen 2010: 895).

Merdiven Yönteminin temel özellikleri ise aşağıdaki şekilde sıralanabilir (Elitaş vd. 2008: 182);

- Merdiven kayıt yöntemi devlet muhasebesi için kullanılmıştır.

- Devletin gelirleri ve giderleri esastır. Bu açıdan merdiven kayıt yöntemi özellikle de vergi gelirlerinin toplanması ve harcanması esasına dayanmaktadır.

- Her bir eyalete ait vergi, toplam vergi gelirlerinin ve vergi türlerinin alt alta yazılması yoluyla hesaplanır ve tahmin edilir. 
Uluslararası Yönetim Iktisat ve Işsetme Dergisi, ICAFR 16 Özel Saylsı Int. Journal of Management Economics and Business, ICAFR 16 Special Issue

- Harcama türleri ve tutarlarının alt alta siralanması esastır.

- Yöntem muhasebenin tahakkuk esasına göre uygulanmaktadır. Ancak tahakkuk maddesi yapılmadan işlemlerin yürütüldüğü bilinmektedir. Tahakkuk tutarı ise başka bir yerde takip edilmektedir.

- Merdiven kayit yöntemi hem miktar ve hem de tutar yazmaya müsaittir.

- Yöntemin uygulanması ile devletin bir yıllık gelirlerinin tek bir kayıt ile yapılabilmesini sağlanabilmektedir.

Şekil 1: Osmanlı İmparatorluğu yükselme dönemine ait, mutfak giderlerine ilişsin bir muhasebe kayıt örneği

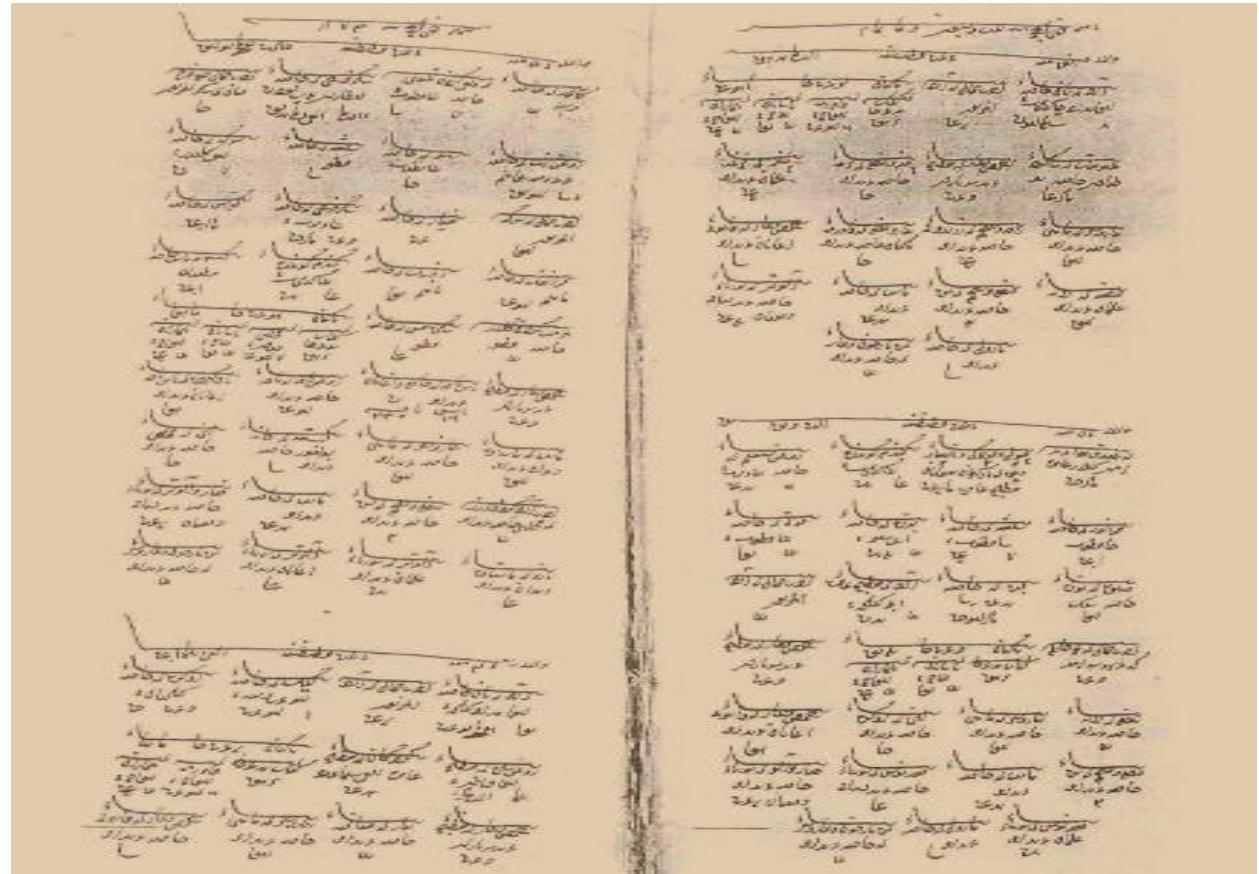

Kaynak: (Elitaş vd. 2008: 368).

Osmanlı arşivlerinden günümüze yaklaşık 95 milyon belge ulaşmıştır. $\mathrm{Bu}$ belgelerin yaklaşık yüzde yirmisi hasarlıdır. Hasarlı olmayan ve yararlanılabilen belgelerin ise 15 milyon adedinin muhasebe ile ilgili olduğu tahmin edilmektedir. $\mathrm{Bu}$ belgelerin, muhasebe kaydının dayanağı olan belgeler ve muhasebe bölümleri arası bilgi aktarma belgeleri olduğu söylenebilir. Osmanlıdan günümüze ulaşan defter sayısı ise 360.000 adettir. Bu defterlerin ise yarısı yani 180.000 adedinin muhasebeye ilişkin olduğu tahmin edilmektedir (Elitaş vd. 2008: 143). Tüm bu rakamlar Osmanlı İmparatorluğu'nun muhasebeye verdiği önemi kanıtlar niteliktedir.

Özellikle XV. Yüzyıl Osmanlı İmparatorluğunun en hareketli dönemlerinden biri olmuştur. Beş padişahın hüküm sürdüğü, ilk altın paranın basıldığı ve İstanbul'un Fethi gibi önemli olayların yaşandığı bu yüzyıldaki hareketlilik elbette muhasebe sistem ve 


\section{Uluslararası Yönetim İktisat ve İsletme Dergisi, ICAFR 16 Özel Sayısı \\ Int. Journal of Management Economics and Business, ICAFR 16 Special Issue}

işleyişinde de kendini göstermiştir. 1494 yılında Hacı Atmacaoğlu Muhyeddin Muhammed tarafından kaleme alınan Mecma'ül-Kavaid adlı eser, bu durumun önemli göstergelerinden biri olmuştur.

\section{Muhyeddin Muhammed ve Mecma'ü'-l Kavâ'id Adlı Eseri}

Hacı Atmacaoğlu Muhyeddin Muhammed 15. Yüzyılda yaşamış ve Fâtih Sultan Mehmet ve 2. Sultân Bayezid-î Velî (II. Bayezid) dönemi alimlerinden olarak bilinmektedir. Muhyeddin Muhammed'in adı çeşitli kaynaklarda, Muhyiddin Muhammed b. Hacı Atmaca al-Kâtib, Muhyiddin Mehmed b. Hacı Atmaca, Hacı Muhyiddîn ibn Mehmed ibn Hacı Atmaca, Hacı Muhyiddin Mehmed İbn Hacı Atmaca gibi farklı şekillerde belirtilmiştir (Özçelik, 2009: 1).

Muhyeddin Muhammed'in hayatı hakkında günümüze ulaşan belge ve bilgiler oldukça yeterizdir. Ancak kaleme aldığı Mecma'ü’-l Kavâ'id eser incelendiğinde yazar hakkında bir takım bilgilere ulaşmak mümkündür.

Hacı Atmacaoğlu Muhyeddin Muhammed'in doğum yeri, doğum tarihi ve ölüm tarihi ne yazık ki bilinmemektedir. Kaleme aldığı eserini 1494 tarihinde tamamlayan yazarın bu tarihte sağ olduğu anlaşılmaktadır. Ayrıca kâtip unvanına sahip olduğu dolayısıyla bir muhasip ve kâtip olduğu bilinmektedir. Muhyeddin Muhaemmed, Mecma 'ü'l-Kavâ‘id adlı eserinde yer alan bilgiler 1şı̆̆ında yazarın çok iyi derecede Arapça ve Farsça dillerini bildiğini, zamanında gittikçe önem kazanan bir bilim dalına ilgisiz kalmamış iyi bir muhasip ve bilim insanı olduğu sonucuna varılabilir. Mesleği ile ilgili eserindeki ifadelerden bir diğer bilgi ise meslekte tecrübe sahibi olup, olgunluk dönemine gelinceye kadar divan beyleri ve rakamlar konusunda ehil olan kimselerle görüştüğü, uzun zaman onların hizmetinde bulunduğudur. (Özçelik, 2009: 2-3).

Hacı Atmacaoğlu Muhyeddin Muhammed yazdığı esere Mecma'ü’l-Kavâ'id adını vermiștir. Mecma'ü’l-Kavâ'id kaidelerin toplandığı yer anlamına gelmektedir. Eser özellikle dönemin muhasebecileri için kaleme alınmıştır. Eserde muhasebecilerin ve mali işlerle ilgilenen kişilerin ihtiyaç duyabileceği kural ve kaideler sistemli bir şekilde açıklanmıştır. Eser ayrıca Muhasebe matematiği kitabı olarak da kabul edilmektedir bu eser gerek yazıldığı tarih ve coğrafya gerekse içerdiği konular açısından Türk muhasebe tarihi açısından şüphesiz çok önemlidir (Can ve Küçüker, 2013: 364).

Mecma'ü'l-Kavâ‘id'in yazılma nedeni mesleğe yeni başlayan muhasiplerin faydalanabileceği, ve tüm hesap kurallarını içeren Türkçe bir eser kaleme almaktır. Yazar bu alanla ilgili birçok kitap değerlendirmiştir. Ancak, bunların Türkçe olmamasından (Arapça ve Farsça olmasından) dolayı yeteri kadar faydalı olamayacağı tespitinde bulunmuştur. Özetle eserin yazılış gayesi yazara göre gayet önemli ve şerif bir ilim olan muhasebe hakkında faydalı olabilecek Türkçe bir eser ortaya koymaktır (Fazlıŏlu, 2003'ten akt. Özçelik, 2009: 4).

Yazarın ilgili dönemdeki diğer bazı eserlerden farklı olarak kendi isteği ile kaleme aldığı Mecma'ü'l-Kavâ'id adlı eser 3 ana bölümden oluşmaktadır. Bölümlerde genel hatları ile şu konular işlenmektedir (Gökdoğan, 2002: 268);

"Birinci bölüm tam sayılar üzerinedir ve on altı fasıldan oluşmuştur. Bu bölümde, siyakat rakamları, Hint rakamları (on tabanlı sayı sisteminin rakamları) tanıtılarak, toplama, çıkarma, çarpma ve bölme işlemleri pratik çözümleri ve örnekleri ile 


\section{Uluslararası Yönetim İktisat ve İşletme Dergisi, ICAFR 16 Özel Sayısı Int. Journal of Management Economics and Business, ICAFR 16 Special Issue}

anlatılmıştır. Yine bu bölümde borçlunun mallarının alacaklılar arasında bölünmesi üçte bir, dörtte bir, beşte bir onda birini almak gibi konular açıklanmıștır.

On altı fasıldan oluşan ikinci bölüm kesirler üzerinedir. Yazar bu konunun bilinmesinin hesap uzmanları için gerekli ve önemli olduğunu belirtmiştir. Kesirlerle kesirlerin çarpılması, kesirlerle tam sayıların çarpılması ve bölünmesi gibi konular bu bölümde anlatılmıştır. Dönemin ticaret hayatında kullanılan ölçü birimleri, paralar ve vergilerin hesaplanması gibi konular da bu bölümde yer almıştır. Bu durum ve içerik eseri, dönemin ticaret ve sosyal hayatı ile ilgili önemli bir kaynak durumuna getirmektedir. Örnekler ve pratik çözümleri ile anlatılan bu konuların hesap iși ile uğraşanlar için çok önemli olduğu eserde sıklıkla dile getirilmiştir.”

Üçüncü bölüm ise "mesāyil-i şettā” yani çeşitli meseleler üzerinedir. Muhyeddin Muhammed bu bölümün eskilerin kitaplarında pek fazla bulunmadığını belirtir. Bu bölümde çözümlü 40 problem yer alır. Her bir problem "mesele" olarak adlandırılmıştır. Gümrüğün hesaplanması, havuz problemleri, alan problemleri, mal bedellerinin hesaplanması, mukâta'a ve tımar arazilerinin gelirlerinin hesaplanması, bir miktar paranın üç yılda kârıyla ne kadar olacağı vb muhasiplerin günlük sorunların çözümünde kullanabilecekleri problemler bu bölümde yer alır (Özçelik, 2009: 9).

\section{Şekil 2: Mecma'ü'l-Kavâ‘id adlı eserden bir görüntü.}

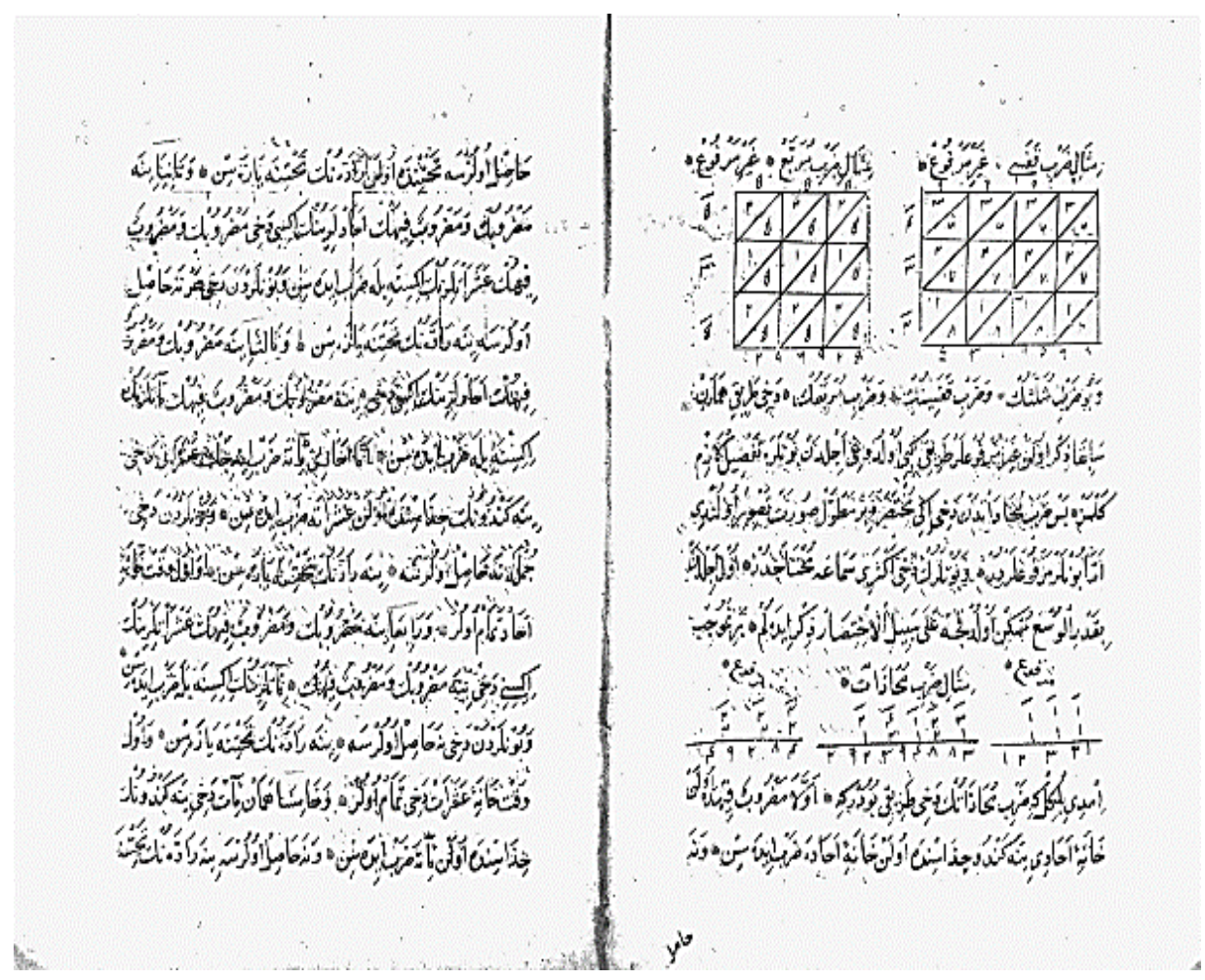

Kaynak: İz. Koyunoğlu Kütüphanesi, Milli Kütüphane Mikro Film Arşivi, Arşiv No: A1467 
Uluslararası Yönetim İktisat ve Işsetme Dergisi, ICAFR 16 Özel Saylsı

Int. Journal of Management Economics and Business, ICAFR 16 Special Issue

\section{Kârın Sermaye Paylarıyla Orantılı Dağıtımına İlişsin Çözümlü Örnek}

Mecma ‘ü'l-Kavâ'id adlı eserin son bölümünde yer alan ve her biri "mesele” olarak adlandırılan 40 çözümlü örnekten 11. si olan örnek XV. Yüzyıl Osmanlı dönemi muhasebesi hakkında bazı ipuçları vermektedir. Söz konusu 11. Mesele günümüz Türkçesine çevrilerek incelenmiştir.

Örnekte, dönemin benzer eserlerinde de olduğu gibi. Amr, Bekr ve Zeyd adlı karakterleri kullanılmıştır ve bu üç kişinin ortak olarak bir yıl boyunca ticaret yaptıktan sonra ortaya çıkan kârın, başta koydukları sermaye dikkate alındığında nasıl dağııılması gerektiği hesaplanarak anlatılmıştır.

Söz konusu mesele eserde şöyle geçmektedir;

\section{Mesele:}

"Ve eğer sorsalar ki;

Zeyd'in bin altt yüz akçast olup ticarete başlasa ve kırk beş gün sonra Amr iki bin üç yüz akça getirip onunla ortak olsa sonra, Bekr de bu ktrk beş günden on beş gün sonra gelip o da iki bin ü̧ yüz altmış akça getirse ve bu meblağl birbirine karıştırıp ortaklık üzerine bir yll müddetçe ticaret yapsalar ve bu meblağdan sekiz yüz kırk akça kâr (kazanç) elde edilse ve bu kârdan bunların her birisinin hesapla hisseleri ne olur diye sorsalar"

“Önce bu söylenenlerin gün sayılarını bulasın. Mesela Zeyd'in gün sayısı 360'dır. Ve Amr'ı gün adedi 315, Bekr'in gün sayısı da 300'dür. Zira ortaklık halinde (durumunda) bunların gün sayıları önemlidir. Ve bunların her birinin kendilerinin sermayelerine ayrı ayrı (ferdi olarak) çarpasın. Ve bu çarpım sonuçları ne kadar olursa toplayasın ki o toplamın sonucunun bölen olması gerekir."

İlk çarpım örnekleri:

\begin{tabular}{|c|c|}
\hline 1600 & 2300 \\
\hline 360 & 315 \\
\hline 76000 & 724500 \\
\hline
\end{tabular}

"Ve bu üçüncü çarpma sonucunun toplamı 2008500 olur. Ve bu toplam bölendir. Bundan sonra bu çarpım sonuçlarının da her birini ayrı ayrı söylenen kâr meblağı ile çarpasın."

\section{İkinci çarpım örnekleri:}

\begin{tabular}{|c|c|c|}
\hline 576000 & 724500 & 708000 \\
\hline 840 & 840 & 840 \\
\hline 483840000 & 608580000 & 4720000 \\
\hline
\end{tabular}

"Ve bu çarpım sonuçları bölünendir. Bundan Sonra ikinci çarpım sonuçlarını bölünen edip birinci çarpım sonuçlarının toplamını bunlara bölen edip bunu da ayrı ayrı bölesin. Ve her bölümde sonuç ne olursa her birinin hisseleri odur." 
Uluslararası Yönetim İktisat ve Işsetme Dergisi, ICAFR 16 Özel Saylsı

Int. Journal of Management Economics and Business, ICAFR 16 Special Issue

\begin{tabular}{l|cl|cl|c}
42562 & Zeyd'in Hissesi & 45 & Amr'n Hissesi & 24 & Bekr'in Hissesi \\
482840000 & $\mathbf{2 4 0}$ & 608580000 & $\mathbf{3 0 3}$ & 594720000 & $\mathbf{2 9 6}$ \\
20850000 & & 600850000 & & 200850000 & \\
2008500 & & 2008500 & & 200850 & \\
20085 & & &
\end{tabular}

"Ve bundan sonra eğer bunların doğruluğunu ve yanlışlığını bilmek istersen bu hisseleri toplaman gerekir. Eğer bunun toplamından o kâr olan sekiz yüz kırk çıkarsa doğrudur.”

839,875

"Şimdi bu toplama diğer sekizde bir daha gerekir ki asıl kar buluna. Şimdi bundan sonra bölünendeki kalanı da toplayasın. Ve eğer bu toplam da önceki toplama sonucunun sekizde bir şekline uyarsa doğrudur. Ve eğer fazla ya da eksik olursa doğruluktan yoksun olduğunun delilidir. Sonra bu kalanların tamamı da sekizde bir dirhem oldu. Şimdi bu da anlaşıldı ki bu kârdan hesapla Zeyd'e iki yüz kırk akça ve sekizde yedi dirhem, Amr'a üç yüz üç akça ve Bekr'e de iki yüz doksan altı akça düşüp bu hepsinden sekizde bir dirhem kalır."

Görüldüğü üzere, Mecma‘ü’l-Kavâ‘id adlı eserin üçüncü bölümünde yer alan bu örnek günümüz şirketler muhasebesi uygulamalarındaki hesaplamaları ile benzerlik göstermektedir. Örnekte öncelikle gün sayılarını belirleyen yazar zaman temelli bir hesaplamaya gitmiş ve ortakların ortaya koydukları sermaye miktarlarını da hesaplamaya katarak, bir yılın sonunda elde edilen 840 akçalık kârın her bir ortağa ne miktarda dağıtılması gerektiğini belirtmiştir. Örneğin sonunda çözümün sağlamasını da yapan yazar bu noktada küsurat hesaplamalarını da hesaba katarak bölümden kalan miktarları da ortaklar arasında paylaştırmıştır.

\section{Sonuç}

15. yüzyıl Osmanlı âlimlerinden olan Muhyeddin Muhammed dönemin muhasebecilerinin faydalanacağı kaynakların Türkçe olmadığını ve yetersiz olduklarını tespit etmiş ve bu gerekçe ile 1494 yılında Mecma ‘ü’l-Kavâ‘id adlı eseri kaleme almıştır.

Eserin Luca Pacioli'nin kaleme aldığı "Summa de Arithmetica, Geometria, Proportioni Et Proportionalita" ile aynı yılda tamamlanmış olması oldukça önemli bir noktadır. Zira bu durum Türklerin en az diğer gelişmiş medeniyetler kadar sağlam bir muhasebe alt yapısına sahip olduğunu ve Türklerin muhasebe tarihi sahnesine çıkmasının oldukça eski tarihlere dayandığını gösterir. Bununla birlikte, Türklerin 15. yüzyılda 
Uluslararası Yönetim İktisat ve İşletme Dergisi, ICAFR 16 Özel Sayısı
Int. Journal of Management Economics and Business, ICAFR 16 Special Issue

muhasebe terimlerini ve kayıt düzenine ilişkin kavramları kullanması, daha önceden de bu gibi konularla uğraştığının göstergesi olarak kabul edilmelidir zira bir bilim dalına ilişkin standartlar uzun yılların deneyimi sonucunda ortaya çıkar, olaylar yaşanmadıkça bir bilim dalı hakkında kaide konulması oldukça zordur. Bu bağlamda Osmanlı dönemi muhasebe uygulamalarının önceki dönem Türk Devletlerinde kullanılan yöntem ve uygulamaların devamı olduğu söylenebilir.

Mecma'ü'l-Kavâ‘id eserde dönemin muhasebecilerinin ihtiyaç duyduğu ve faydalanması gereken kural ve kaideler sistemli bir şekilde açıklanmıştır. Muhasebe matematiği kitabı olarak da kabul edilen bu eserin, yazıldığı tarih, coğrafya ve içerdiği konular dikkate alındığında Türk muhasebe tarihi açısından oldukça önemli olduğunu söylemek mümkündür. Eserde kullanılan bazı hesaplama kural ve yöntemleri günümüzde hala geçerliliğini korumaktadır. Çalışmada yer verilen "mesele" de bu durumun bir göstergesi olarak kabul edilebilir. Zira bu mesele özellikle de günümüz şirketler muhasebesi hesaplamaları ile paralellik arz etmektedir.

\section{Kaynaklar:}

Can, A. V. \& Esen, S. (2010), "Osmanlı Muhasebe Sistemi ve 1530 Yılına İlişkin Yapılan Kayıtların Işı̆̆ında Bir Osmanlı Livası: Prizren", 2. Uluslararası Balkanlarda Sosyal Bilimler Kongresi, Prizren.

Can, A.V. \& Küçüker, M. (2013), Muhyeddin Muhammed'in Mecma‘ü’-1 Kavâ‘id Adlı Eserinin Türk Muhasebe Tarihi Açısından Önemi, 11. Uluslararası Türk Dünyası Sosyal Bilimler Kongresi, Celalabat, KIRGIZISTAN.

Elitaş, C., Güvemli, O., Aydemir, O., Erkan, M., Oğuz, M., \& Özcan, U., (2008), Osmanl imparatorluğunda 500 Yll Boyunca Kullanılan Muhasebe Yöntemi: Merdiven Yöntemi, Maliye Bakanlığı Yayınları No: 2008/377.

Fazlıŏglı, İ. (2003), “Osmanlı Döneminde Bilim Alanındaki Türkçe Telif ve Tercüme Eserlerin Türkçe Oluş Nedenleri ve Bu Eserlerin Dil Bilincinin Oluşmasındaki Yeri ve Önemi”, Kutadgu Bilig Felsefe-Bilim Araştırmaları Dergisi, no:3, s.151184.

Gökdoğan, M. (2002), “Osmanlılarda Matematik”, Türkler, Yeni Türkiye Yayınları, Cilt: 11, , s.267-276, Ankara.

Güvemli, O. (1995), Türk Devletleri Muhasebe Tarihi, 1. Cilt, Avc1ol Yayınları, İstanbul.

Özçelik, S. (2009), Muhyeddin Muhammed'in Mecma 'ü'-l Kavâ'id Adlı Eseri (GirişInceleme-Metin-Sözlük), Yayınlanmamış Doktora Tezi, İstanbul Üniversitesi Sosyal Bilimler Enstitüsü, Türk Dili ve Edebiyatı Anabilim Dalı, İstanbul.

Pur, H. P. (1995), "Çăglar Boyunca Muhasebe Mesleğinde Statü ve İşlev Değişimleri”" Muhasebenin Tarihsel ve Çăgdaş Konumlarından Geleceğine Bakış 500. Yll, TÜRMOB Yayınları: 23, Ankara. 